\title{
Aproxime-se: Programa de Extensão Universitária em EaD
}

\section{Jussara Bueno de Queiroz Paschoalino ${ }^{1 *}$, Marcio Boaventura Junior ${ }^{2}$, Marcela Rosa de Lima Machado ${ }^{3}$, Wagner J. B. Corradi ${ }^{4}$}

\footnotetext{
1 Investigadora/Doutora em Educação/Professora Pesquisadora, do Centro de Apoio à Educação a distância/Universidade Federal de Minas Gerais. Av. Antônio Carlos, 6627 - Campus Pampulha - Unidade Administrativa III Belo Horizonte - MG/Brasil.jussarapaschoalino@yahoo.com.br
}

\footnotetext{
${ }^{2}$ Investigador/Mestre em Educação/ Professor Pesquisador, do Centro de Apoio à Educação a distância/ Universidade Federal de Minas Gerais. Av. Antônio Carlos, 6627 - Campus Pampulha - Unidade Administrativa III Belo Horizonte - MG/Brasil. marcioboaventura@gmail.com
}

${ }^{3}$ Investigadora/Mestranda em Educação/ Professora Pesquisadora, do Centro de Apoio à Educação a distância/ Universidade Federal de Minas Gerais. Av. Antônio Carlos, 6627 - Campus Pampulha - Unidade Administrativa III Belo Horizonte - MG/Brasil.marcelarlm@gmail.com

${ }^{4}$ Investigador/Doutor em Física/ Diretor de Educação a Distância da Universidade Federal de Minas Gerais. Av. Antônio Carlos, 6627 - Campus Pampulha - Unidade Administrativa III Belo Horizonte - MG/ Brasil. wbcorradi@ufmg.br

\section{Resumo}

Este estudo analisa um programa de Extensão Universitária chamado "Aproximese", em que a própria etimologia do nome traz o aspecto central da ação realizada.Os participantes são alunos bolsistas de extensão universitária em Educação a Distância da Universidade Federal de Minas Gerais. O objetivo deste artigo é permitir a discussão dos aspectos relacionados à orientação acadêmica realizada na extensão, destinado a estudantes de graduação de formação em Educação a Distância. A educação universitária compreende as dimensões interligadas de ensino, pesquisa e extensão. No entanto, na educação a distância ainda se constata o predomínio do ensino em detrimento à pesquisa e à extensão. O Programa Aproxime-se tem o objetivo diminuir as lacunas na formação de estudantes e de promover o pertencimento à universidade. Ao mesmo tempo, possibilita um diálogo entre a universidade e as cidades-polo e coloca os alunos bolsistas como protagonistas diante da realidade de sua cidade. A segunda edição desse Programa evidenciou as marcas positivas de aprendizagem para os alunos bolsistas, de abertura de diálogo e de aproximação das cidades-polo com a universidade.

Palavras-chave: Extensão universitária; Educação a distância; Aproxime-se. 


\title{
"Aproxime-se": Academic Extension Program in Distance Education
}

\begin{abstract}
This study analyses an Academic Extension Program named "Aproxime-se" (Approaching). Its name's etymology brings the central aspect of the action performed. The participants are scholarship students in Distance Education at the Federal University of Minas Gerais. The purpose of this article is to stimulate the discussion of aspects related to academic orientation conducted on Extension Program, intended for graduation's students in Distance Education. The academic education consists of the interconnected dimensions of teaching, research and extension. Even though the Distance Education still notes the predominance of teaching over research and extension. The Program aims to decrease the gaps in the students' learning and to promote belongingness in the university. At the same time, it enables a dialogue between the university and the cities that participate in the Program, and places the scholarship students as protagonists before the reality of their city. The second edition of this Program showed positive learning marks for scholarship students, dialog's opening and approximation of the cities that participate in the Program with the university.
\end{abstract}

Keywords: University extension; Distance Education; "Aproxime-se". 


\section{Introdução}

Este estudo analisa a perspectiva de orientação acadêmica realizada com os alunos bolsistas na extensão universitária em Educação a Distância (EaD) da Universidade Federal de Minas Gerais. Assim, o objetivo deste trabalho é refletir e possibilitar a discussão sobre uma ação de extensão, que visa à formação universitária dos alunos da Educação a Distância.

A formação universitária compreende as dimensões interligadas do ensino, da pesquisa e da extensão. Diante das lacunas na formação dos alunos na extensão universitária, os desafios de equidade na formação superior a distância em comparação com o ensino presencial foram identificados. Com esse intuito foi construído um Programa de Extensão universitária denominado "Aproxime-se".

A escolha do nome traz em sua etimologia o aspecto central do referido programa. A capacidade de sentir próximo, de aconchegar e, principalmente, de possibilitar o movimento em direção estabelecida, no caso, a formação plena. O programa foi elaborado pelo Centro de Apoio a Educação a Distância da Universidade Federal de Minas Gerais - CAED e realizado com o apoio da Equipe Multidisciplinar.

O público-alvo foi de10alunos de graduação da EaD de diferentes cidades do Estado de Minas Gerais, no ano de 2013, e teve sua continuidade com mais 10bolsas de extensão universitária no ano de 2014. Dessa forma, o Programa Aproxime-se teve como objetivo geral: empreender a extensão universitária nas cidades-polo da Universidade Aberta do Brasil - UAB, para estabelecer a interlocução entre os saberes acadêmicos e locais e contribuir com a formação do aluno da graduação na modalidade a distância com a sua inserção na extensão universitária bem como ao acesso a partir de ações voltadas para a formação tecnológica, social, cultural e científica.

Dentre os objetivos específicos do "Aproxime-se" destacamos: criar oportunidades para que os alunos matriculados em diferentes cursos da modalidade a distância possam se integrar e se relacionar a partir de atividades ou de formações curriculares transversais. A perspectiva do Programa Aproxime-se corrobora com os pensamentos de Mill e Pimentel (2010) sobre os espaços universitários que a educação a distância precisa conquistar.

Na sua segunda edição, o Programa Aproxime-se vem consolidando um trabalho inovador de estreitar as relações entre a universidade e as cidades-polo. Nesse movimento, o trabalho de extensão universitária na educação a distância conseguiu 
dinamizar as relações entre as cidades-polo e o saber universitário, principalmente, pelo destaque da visualização de divulgar a existência dos cursos a distância oferecidos pela Universidade Federal de Minas Gerais.

A pesquisa realizada permitiu constatar a melhoria na produção escrita dos alunos bolsistas participantes e também a possibilidade de diálogo entre a universidade e as cidades-polo de problemas atuais no seu contexto.

\section{Metodologia}

A metodologia de pesquisa utilizada para compreender as repercussões do Programa Aproxime-se foi a abordagem qualitativa. A pesquisa possibilitou coletar significados dos participantes adiante da realidade e da resposta das cidades-polo do Programa efetivado. Assim, de acordo com Creswell (2007), os instrumentos utilizados valorizaram a observação, o diário de bordo, os relatórios produzidos pelos alunos bolsistas e as entrevistas semiestruturadas. As fidedignidades dos resultados alcançados foram cuidadosamente acompanhadas e analisadas no processo da pesquisa. Foram observados todos os cuidados metodológicos nos registros das informações coletadas e preservada a garantia do caráter de anonimato dos participantes.

\section{Resultados e discussão}

O programa foi realizado pelo CAED com o apoio da Equipe Multidisciplinar ao longo do primeiro ano em que foi executado, 2013. Além desses profissionais, o Programa contou com 10 bolsas de extensão, que foram contempladas em edital público da PróReitoria de Extensão da Universidade Federal de Minas Gerais (PROEX/UFMG). O edital para Fomento de Bolsas de Extensão da PBEXT 2013 teve como principal objetivo:

[...] apoiar o desenvolvimento de programas/projetos de extensão em acordo com as diretrizes de extensão da UFMG; estimular a participação dos alunos nos programas/projetos de extensão, destinados a ampliar e fortalecer a interação da universidade com a sociedade e contribuir na sua formação técnico-científica, pessoal e social. (PROEX/UFMG, 2012). 
A proposta do Programa Aproxime-se continha quatro projetos articulados: Cidadania; Ficção \& Realidade; Saberes Transversais e Virtualidade. Esses projetos tiveram em comum o fato de preverem a construção do conhecimento de modo inter e multidisciplinar, ultrapassando as barreiras das áreas de conhecimento, numa dimensão didática transdisciplinar e sempre pensando no diálogo entre os saberes científicos e os saberes locais dos alunos e demais participantes.

A garantia das bolsas de extensão universitária para os alunos da EaD foi um passo importante no processo de institucionalização da modalidade no sentido de garantir a eles acesso ao tripé ensino, pesquisa e extensão. As bolsas - direcionadas aos alunos dos cursos da Universidade Aberta do Brasil/ UFMG - foram preenchidas através de editais públicos de seleção amplamente divulgados na página do CAED/UFMG bem como nas plataformas dos cursos. No total, foram publicados três editais para preenchimento das 10vagas em 2013.

Inicialmente proposto para 10 cidades-polo, o programa encontrou algumas dificuldades de implementação, o que acabou ocasionando a redução dos polos contemplados em 2013, passando para nove polos. O principal motivo para essa redução foi a ausência de inscritos no polo de Frutal, o que acabou resultando na seleção de dois bolsistas para o polo de Formiga.

Essa situação demonstrou que a extensão ainda não é uma cultura presente nos cursos de Educação a Distância. A EaD teve expansão nas últimas décadas, no entanto, muitas vezes, ainda não tem a visibilidade desejada. (Neves et al., 2012). Nessa lógica, foi possível constatar que muitos bolsistas ingressaram sem compreender, de fato, em que consiste a extensão universitária e nem quais são as vantagens da participação no programa para a sua formação.

As dificuldades na EaD perpassam por vários aspectos para a sua efetiva realização. (Mill e Pimentel, 2010). A ausência de recursos na universidade destinados especificamente para o desenvolvimento de Programas e Ações de Extensão Universitária na Educação a Distância gerou algumas dificuldades para o desenvolvimento desse projeto, que precisaram ser compensadas, principalmente com o apoio total do CAED, como também da coordenação dos polos e da prefeitura dos municípios envolvidos. Em termos de recursos humanos, foi necessário mobilizar um processo de captação de voluntários capacitados e interessados a lecionar os minicursos nos polos de forma gratuita. 
Para o desenvolvimento dos trabalhos, a equipe de professores orientadores do CAED contou com a ajuda dos professores pesquisadores que estiveram conjuntamente no acompanhamento e orientação dos bolsistas. Nesse sentido, os trabalhos realizados em conjunto entre os membros da equipe visavam garantir as perspectivas da universidade ao trabalharem o ensino, a pesquisa e a extensão em cada encontro de forma indissociável e dialógica.

A constituição de uma equipe de trabalho para a execução desse Programa inovador exigiu da parte gestora os cuidados necessários de afinar as concepções teórico-metodológicas e ao mesmo tempo instaurar um espaço de interlocução e criatividade. Dessa forma, no Programa Aproxime-se, os participantes da equipe são vistos como sujeitos de saberes e interventores da realidade.

Para dinamizar os aspectos de formação e possibilitar a criatividade dos participantes da equipe, foram realizadas inicialmente duas capacitações pela equipe gestora. Uma das capacitações foi com os bolsistas e voluntários e a outra foi realizada com os coordenadores de polo. Nessas capacitações privilegiou-se o:

[...] reinventar lideranças, promovendo lógicas de partilha e desvelando veios opressores remanescentes nas dinâmicas pessoais, sociais e laborais passam pela capacidade de ouvir e de dar a palavra, numa lógica conflitual e empoderadora. (MONTEIRO, 2012, p.180).

A possibilidade do diálogo e da partilha de saberes entre os participantes durante as capacitações foram alterando o desenho inicial do Programa Aproxime-se. Os limites da ação do Programa eram impostos pelo desejo de ampliar os eventos na medida do possível.

A "Capacitação Aproxime-se" direcionada aos bolsistas e voluntários oferecida pelo Centro de Apoio à Educação a Distância teve por objetivo desenvolver e discutir os aspectos do trabalho em relação à atuação na operacionalidade do mesmo bem como na formação teórica necessária para uma boa fundamentação das atividades exercidas pelos envolvidos. Através de atividades educativas, questões atuais de elucidação dos problemas vivenciados pela comunidade e de fortalecimento da formação dos envolvidos no Programa foram debatidas e refletidas pelos participantes. Além disso, a "Capacitação: Aproxime-se" objetivou realçar as possibilidades formativas dos envolvidos, a partir do incentivo da realização de cursos, atividades acadêmicas, culturais e tecnológicas.

No primeiro momento do encontro, foram promovidas palestras com duas horas 
de duração sobre os eixos teóricos do Programa Aproxime-se:

Cidadania: as principais questões acerca da cidadania e o seu pleno exercício na contemporaneidade foram debatidos pela professora Marcela Rosa de Lima Machado, que instigou o grupo de participantes a elucidarem conjuntamente sobre as questões: etimológica, histórica e política em torno do termo. Outro aspecto abordado foi questionar e incentivar os participantes a refletirem sobre as possibilidades de se vivenciar em nossa sociedade a plenitude de nossos direitos como cidadãos.

Ficção \& Realidade: Apoiando-se na Filosofia, na Teoria da Arte e na Teoria da Comunicação, o professor Márcio Boaventura Jr. ministrou uma palestra na qual suscitou os participantes a se questionarem porque o homem é o único animal que produz ficção. Por que fazemos ficção? Por que criamos ilusões de realidades, espaços e pessoas inexistentes para contar histórias que nunca aconteceram ou para recontar histórias humanas? Por que produzimos imagens que não se encontram na natureza, de forma a materializar visualmente as ideias que temos na cabeça? Por que escrevemos roteiros, filmamos, editamos, fotografamos e elaboramos vídeos?

Todos os outros seres sencientes interagem com a realidade material, e apenas com ela - enquanto o homem, além de modificá-la, procura também criar uma nova perspectiva de realidade: a ficção. Além disso, foi debatido como podemos, através do conhecimento da linguagem cinematográfica, melhor compreender as visões críticas e políticas que uma obra de cinema tem a fornecer aos seus espectadores.

Saberes Transversais: Para o trabalho com essa temática, a professora Jussara Bueno de Queiroz Paschoalino buscou entrelaçar as noções de informação, conhecimento, comunicação e tecnologia, bem como debates em torno de tempo, espaço, e ciberespaço e experiência contemporânea. Usando como escopo e pressuposto os conceitos das diretrizes curriculares brasileiras, foram trabalhadas as possibilidades de transversalidade dos saberes em um programa de extensão universitária. Já que a transversalidade nos fala sobre a possibilidade de se estabelecer, na prática educativa, uma conexão entre o processo de aprender na realidade e sobre a realidade.

Virtualidades: Para quem cursa uma graduação na modalidade EaD, a experiência de se utilizar a rede como caminho para a aprendizagem não é nova. Porém, muitas vezes essa vivência é feita de maneira mecânica e não crítica. O 
objetivo dessa palestra foi mostrar as possibilidades que a virtualidade pode apresentar como espaço de formação humana. Para a professora Priscila Rezende Moreira, que ministrou a palestra, é preciso refletir sobre a virtualidade como um espaço capaz de promover sensibilização, emissão de opiniões, palco de debates e compartilhamento de saberes e construções de pensamentos vinculados aos desafios pertinentes a todo cidadão brasileiro, especialmente, no que tange à ordem da educação na contemporaneidade.

Após o primeiro dia de palestras sobre os projetos que compunham o Programa Aproxime-se, realizou-se um relato do retrato político e social dos nove polos no qual o programa estava atuando. O referido retrato foi construído a partir de informações coletadas nos jornais e meios de comunicação virtuais de cada polo, bem como levantamento de informações nos órgãos oficiais dos municípios. Os dados do último censo realizado pelo IBGE também foram consultados. Diante dessas informações, foi possível a construção de um retrato atual das principais questões de cidadania de cada polo e, de acordo com essa realidade, propiciou à equipe do Programa Aproxime-se categorizar, selecionar e apresentar as principais demandas de cada região nas quais a extensão ocorreria. Por último, definiu-se o fluxo de trabalho e as ordenações das metas para o ano de 2013.

Numa proposta similar, a "Capacitação Aproxime-se: Coordenadores dos polos UAB/UFMG", também ofertada pelo CAED, teve, por sua vez, a finalidade de desenvolver e discutir os objetivos, a operacionalização e os aspectos do trabalho dentro do Programa Aproxime-se. A equipe técnico-pedagógica considerou fundamental que os coordenadores conhecessem os pressupostos e propostas do "Aproxime-se", e assim identificassem o papel importante ocupado por eles no processo de desenvolvimento do Programa de Extensão nos polos da UAB/UFMG.

Dessa forma, o encontro procurou contribuir com a formação e qualificação dos coordenadores dos polos envolvidos no Programa Aproxime-se e promover o diálogo e esclarecimento de dúvidas e demais questões entre os participantes. Em um primeiro momento, foram promovidas versões mais curtas de uma hora de duração das palestras sobre os eixos teóricos do Programa Aproxime-se: Cidadania, Ficção \& Realidade, Saberes Transversais e Virtualidades. O objetivo era não só apresentar a proposta dos projetos do Programa para os coordenadores, como implicá-los no processo de formação e informação. Em um segundo momento, foi realizado uma 
reunião onde foram discutidas as melhores datas e locais para realização do evento de extensão nos polos. Por último, foi definido o fluxo de trabalho e a ordenação das metas para o ano de 2013.

Uma capacitação metodológica também foi promovida, direcionada apenas para os bolsistas de extensão do Programa Aproxime-se. Essa formação teve como principal objetivo desenvolver técnicas metodológicas para realização das atividades do Programa bem como outras orientações importantes relacionadas aos trabalhos acadêmicos. Durante o evento foram ministradas oficinas sobre a elaboração de textos científicos, resenhas e análises fílmicas.

Esses espaços de aprendizado despertaram o interesse dos participantes que aderiram ao Programa Aproxime-se. Um dos frutos dessas capacitações foi um convite para atender às demandas da coordenadora de um polo para que o Programa Aproxime-se estreasse a sua primeira atuação num evento maior próprio da cidade denominado: "Inverno Cultural de Campos Gerais." O aceite e a participação do Programa Aproxime-se nesse evento abriu duas perspectivas interessantes. Na primeira, proporcionou a divulgação da Universidade Federal de Minas Gerais em Campos Gerais e, na segunda, estimulou a participação no evento do "Aproxime-se" na referida cidade.

A preparação das ementas e dos minicursos foram cuidadosamente preparados, uma vez realizada a capacitação teórica com os vários voluntários que compunham a equipe do Programa Aproxime-se, e previa encontros quinzenais. Nesses encontros, em equipe, foi construído o desenho dos minicursos que fariam parte da programação do "Aproxime-se" nos polos.

No primeiro encontro, foi esclarecido aos professores voluntários que os minicursos deveriam ser ancorados dentro da égide de um dos quatro projetos do Programa Aproxime-se. Para a elaboração do Plano do Minicurso, além da ementa, as propostas deveriam conter: a) Título; b) Introdução; c) Justificativa; d) Objetivos; e) Fundamentação ou Referencial Teórico; f) Metodologia; g) Cronograma; h) Resultados esperados. i) Número de vagas; j) Material de apoio necessário. Cada minicurso deveria ser planejado para ser executado em quatro horas.

No segundo encontro, os voluntários apresentaram para todos os presentes na reunião sua proposta de minicurso, dando ênfase à justificativa e aos resultados esperados conectados ao eixo em que pretendiam ser inscritos e a temática que seria 
debatida, ou seja, as diversas dimensões do tema proposto. Todo esse trabalho envolveu os diversos saberes para possibilitar repensar a construção do novo, do ideal a ser atingido e, principalmente, com a intencionalidade de romper as barreiras da educação impostas pelo campo físico da universidade.

A construção dessas ementas trazia a esperança de uma extensão universitária, como programa de formação contínua e que, assim, ultrapassasse a conexão do âmbito de cursos pontuais promovidos para a comunidade. Nesse sentido, a equipe gestora teve como concepção que: [...] o papel de educadores organizados e mobilizados para a ação teórico-prática da transformação social inclui a construção conceptual capaz de unificar culturalmente os trabalhadores para a construção de uma nova hegemonia. (Ciavatta e Ramos, 2012, p. 34).

Com essa lógica, as ementas construídas tiveram o crivo de interlocuções que permitiram em conjunto tecer observações, críticas e sugestões. A partir desse trabalho coletivo, a equipe técnico-pedagógica selecionou os minicursos que fariam parte do planejamento oficial do Programa.

No terceiro encontro, foram divididos os minicursos por polo de forma que cada projeto do programa se visse contemplado com ao menos um minicurso por eixo. Os voluntários foram consultados sobre a programação e a cidade de destino. Diante da anuência dos membros da equipe, a agenda oficial do "Aproxime-se" foi elaborada. As divulgações dos minicursos para os membros da equipe do CAED tiveram a coesão da linha do Programa e foram partilhados por todos.

A concretização do Programa Aproxime-se em 2013 abriu perspectiva para o trabalho em 2014. Nesse sentido, as experiências de práticas inovadoras foram se consolidando em cada etapa realizada.

Os resultados da investigação se pautaram na dinâmica realizada no interstício de dois anos consecutivos do Programa Aproxime-se, que abrangeu o período de 2013 e 2014. O referido programa pela sua característica de inovação foi se ajustando num processo contínuo com a própria equipe de trabalho.

O objetivo central de possibilitar uma formação completa dos alunos, que participaram desse programa de extensão universitária demandou da equipe a construção de uma metodologia pautada na abordagem qualitativa, tendo a interseção das dimensões: Ensino, Pesquisa e Extensão para a modalidade da EaD. 
O percurso da construção do trabalho de formação foi se concretizando ao longo do primeiro ano de atuação. As dificuldades encontradas foram paulatinamente sendo revistas e adequadas às realidades. Assim, alguns momentos presenciais com os bolsistas permearam a formação do Programa Aproxime-se, além do contato contínuo pelos diversos meios da tecnologia da comunicação.

As formações envolveram capacitações metodológicas, participações em eventos pedagógicos e também em participações culturais. As orientações aos bolsistas foram realizadas de forma sistemática com o uso de videoconferências semanais e troca de e-mails. As produções acadêmicas dos bolsistas foram acompanhadas pela orientação da construção mensal de: memorial analítico, resenha de textos científicos, resenha de filmes e teve a culminância de produção de artigo científico. Todo esse processo teve o processo virtual como aliado, ao permitir que o "Aproxime-se" mantivesse contato com todos os bolsistas durante a formação.

O foco de formação foram os 20bolsistas de extensão universitária, que compreendeu 10 em cada período de um ano. Vale salientar que, na forma como o Programa Aproxime-se foi idealizado, a sua dimensão extrapolou a alçada apenas dos alunos participantes. Esses alunos tiveram a formação para serem articuladores na sua cidade da visibilidade de a educação a distância vivenciada por eles. Nesse sentido, a parceria com o coordenador de polo foi fundamental para a efetivação do evento do "Aproxime-se" nas cidades-polo.

Para a realização do evento do "Aproxime-se", cada cidade teve sua dinâmica de atuação, entretanto as inter-relações estabelecidas formaram o diferencial, pois cada bolsista conjuntamente com o coordenador de polo traçaram estratégias de ação para a especificidade da sua cidade. Essas articulações possibilitaram as participações de secretários municipais, também de diversos outros representantes dos órgãos municipais nas cidades e, principalmente, da expressiva participação da comunidade em geral nos eventos do "Aproxime-se".

Assim, as especificidades do Programa delinearam um panorama que se ampliou e se complexificou além das atividades oportunizadas de forma esporádica nos cursos de EaD.

A marca do "Aproxime-se" se evidencia pela tríade do ensino, da pesquisa e extensão ao envolver 10 bolsistas de extensão universitária na EaD e também de elevar a condição do Polo UAB a uma instância de ensino, de pesquisa e extensão. O 
CAED tem a consciência das dificuldades na realização deste Programa e dos limites que cerceiam, em apenas 10, o número de bolsistas/cidades que desenvolvem 0 referido Programa. Entretanto, as ações articuladas e acompanhamento dos bolsistas de extensão universitária possibilitaram um crescimento significativo no desempenho dos participantes.

Nessa lógica, a universidade cumpre o seu papel social de disseminação dos conhecimentos, ao mesmo tempo em que favorece a interlocução de vários saberes.

O Programa Aproxime-se possibilitou a abertura para a comunidade reconhecer a presença da UFMG nos polos ao permitir a visibilidade da instituição, abriu perspectivas de parcerias e principalmente interferiu no processo de ensino e aprendizado dos alunos participantes, que tiveram a oportunidade de transcender a proposta curricular dos seus referidos cursos numa perspectiva transdisciplinar.

A avaliação quantitativa constatou um crescimento nos dados apurados nos anos 2013 e 2014. Vale salientar que, do ano de 2014, os dados ainda estão incompletos, pois teremos atividades até no final do mês de dezembro.

Nessa posição, os dados de 2013 demonstraram o esforço conjunto dos membros do CAED, para levar a plenitude à proposta inicial do Programa Aproxime-se. O desejo de realizar o evento em cada cidade-polo com uma equipe robusta deu lugar a encontros simultâneos em três cidades com uma equipe reduzida.

Diante dessa consideração, distingue-se que os esforços múltiplos não tiraram a beleza e muito menos diminuíram a proposta de conhecimentos previamente acordados. No entanto, os desgastes do acúmulo de funções intensificaram o trabalho da equipe.

Os quadros abaixo apresentam o desenvolvimento do Programa Aproxime-se em 2013 e 2014: 
Tabela 1 - Eventos Programa Aproxime-se 2013

\begin{tabular}{|c|c|c|}
\hline \multicolumn{2}{|c|}{ Ano 2013 } & Data dos eventos \\
\hline Cidade & 133 & 28 de setembro \\
\hline Araçuaí & 104 & 19 de outubro \\
\hline Buritis & 154 & 5 de outubro \\
\hline Campos Gerais & 89 & 28 de setembro \\
\hline Conselheiro Lafaiete & 85 & 5 de outubro \\
\hline Corinto & 133 & 28 de setembro \\
\hline Formiga & 141 & 19 de outubro \\
\hline Governador Valadares & 128 & 5 de outubro \\
\hline Montes Claros & 80 & 19 de outubro \\
\hline Teófilo Otoni & & \\
\hline
\end{tabular}

Total de Inscritos: 1047

Fonte: Organização dos autores- 2014.

No ano de 2014, realizamos o evento em três polos:

Tabela 2 - Eventos Programa Aproxime-se 2014

\begin{tabular}{|l|c|r|}
\hline \multicolumn{2}{|c|}{ Ano 2014 } \\
\hline \multicolumn{1}{|c|}{ Cidade } & Número de inscritos & Data dos eventos \\
\hline Campos Gerais & 99 & 16 e 17 de maio \\
\hline Conselheiro Lafaiete & 224 & 30 e 31 de maio \\
\hline Corinto & 236 & 6 e 7 de junho \\
\hline
\end{tabular}

Total de Inscritos: 559

Fonte: Organização dos autores- 2014.

Os dados dos eventos produzidos cresceram na perspectiva das múltiplas ações muitas vezes de forma simultânea. 
Destacamos os movimentos realizados no ano de 2013:

- 37 minicursos abordando a violência em diálogo com Saberes Transversais, Ficção \&Realidade, Virtualidade e Cidadania.

- Nove exibições de filmes com sessões comentadas.

- Nove mesas redondas;

- Quatro encontros de capacitação tanto teórica, quanto metodológica para os bolsistas, voluntários dos programas, coordenadores e funcionários dos polos.

Já no ano de 2014, mesmo em fase de construção já realizamos:

- Quatro encontros de capacitação tanto teórica, quanto metodológica para os bolsistas, voluntários dos programas, coordenadores e funcionários dos polos.

- 10reuniões, uma em cada polo, para orientação pessoal dos bolsistas adiante de pesquisa qualitativa mesclada com as abordagens etnográfica e história de vida que está sendo desenvolvida.

- 19minicursos, em três polos, abordando o tema: Meio Ambiente em diálogo com Saberes Transversais, Ficção \&Realidade, Virtualidade e Cidadania.

- Palestras em três polos que abordaram a Origem do Universo e Traços da Adolescência Contemporânea.

- Três mesas redondas sobre Meio Ambiente, uma em cada polo.

Os dados quantitativos por si só reafirmam a dimensão alcançada pelo referido Programa. Dois aspectos necessitam de explicações. Primeiramente, um programa novo e inovador leva um tempo para que num processo de educação se efetive plenamente. Outro aspecto, no âmbito do quantitativo salienta que, no ano de 2014, apenas nessa primeira etapa, os números de inscritos avançaram em relação a 2013, se analisarmos a proporcionalidade dos mesmos nas cidades em que ocorreram os eventos.

Destacamos o movimento realizado pelos bolsistas e pelos coordenadores dos polos num exercício de difundir e também de criar uma cultura de participação coletiva nas cidades dos eventos. Muitas das cidades participantes não possuem cinema e a comunidade não tem o hábito de prestigiar eventos acadêmicos e culturais. 
A avaliação do Programa Aproxime-se também extrapola a abordagem quantitativa e trouxe vários relatos dos bolsistas e da comunidade das cidades participantes valorizando a oportunidade de vivenciar um pouco da universidade em seus municípios. Nessa perspectiva, qualitativa, os elogios tecidos se pautaram muito na oralidade no momento do evento e nas manifestações escritas, principalmente das bolsistas de extensão universitária da EaD. A dimensão qualitativa também teve uma proposta, via plataforma de internet, de retorno sobre a avaliação. Obtivemos $97 \%$ de argumentos favoráveis e de elogios à iniciativa realizada. Sabemos, no entanto, que para muitos participantes a utilização das tecnologias é um empecilho para a participação efetiva.

Alguns fragmentos ilustram o aspecto qualitativo da avaliação.

Eu, aluna da UFMG e bolsista do programa, tenho muito orgulho de ter UFMG e de "ter me aproximado". (Bolsista, 2013).

Agradeço de coração a todos da equipe do Programa Aproxime-se, aos meus colegas bolsistas, por tudo que me proporcionaram durante o período em que trabalhamos juntos. As viagens, as capacitações, o companheirismo, a amizade, a paciência que tiveram comigo, o carinho com que me receberam, mesmo sendo a mais velha da turma, dei o melhor de mim, acreditando que com um trabalho sério formamos um grupo forte, capaz de atravessar barreiras, obstáculos e conquistar nossos objetivos. (Bolsista, 2013).

Só tenho a agradecer a participação de toda a equipe de professores da UFMG, com a coordenação do Professor Fernando Selmar Rocha Fidalgo, coordenador do CAED, que vieram apresentar um trabalho brilhante e emocionante com muita competência, simpatia e entusiasmo através dos minicursos, discutindo e debatendo sobre o tema Violência na Escola. (Bolsista, 2013).

O Programa Aproxime-se veio trazer para Campos Gerais, sem utopia, uma esperança de que com trabalho, dedicação, parcerias com universidades, como a UFMG, é possível trabalhar a paz dentro das escolas, das famílias. Que a violência possa ser diminuída, desde que trabalhada com responsabilidade e punho forte. (Bolsista, 2013).

Com o Programa de Extensão Aproxime-se, estou tento uma oportunidade única de conhecer, através de pesquisas, a realidade cruel que a sociedade vive atualmente, que é a violência. Conhecer mais de perto o trabalho de extensão que a UFMG proporciona junto aos polos para melhorar a vida dos alunos e da comunidade, promovendo a união e capacitação. Estou feliz por estar participando do "Aproxime-se", por ser um projeto pioneiro que favorece a aproximação entre universidade e 
sociedade, além da emancipação teórica e prática dos estudantes. (Bolsista, 2013).

As diversas manifestações de carinho para com a formação oferecida pelo Programa Aproxime-se se deram em todos os momentos. De forma efetiva, nas dinâmicas desempenhadas nos eventos deixaram transparecer com evidência o crescimento e a habilidade dos alunos bolsistas frente às demandas realizadas. Por outro lado, a procura da comunidade para a participação no evento do Programa Aproxime-se instaurava uma nova etapa de consolidar o ensino, a pesquisa e a extensão na EaD.

\section{Conclusão}

Os resultados deste trabalho evidenciaram o alcance dos objetivos previstos. Diante das boas práticas realizadas com os alunos bolsistas da graduação da EaD em 2013, novas bolsas de extensão foram conquistadas para o ano de 2014. O Programa Aproxime-se vem se solidificando a cada dia, num movimento simultâneo de formação dos bolsistas e, ao mesmo tempo, da própria equipe realizadora. A extensão universitária nos cursos de EaD é possível. A relevância do estudo mostrou a inovação do Programa Aproxime-se e também a análise do trabalho realizado permitiu consolidar a formação plena dos alunos da modalidade da EaD.

A conclusão da pesquisa possibilitou compreender que a extensão universitária na modalidade da Educação a Distância é possível e necessita de divulgação para que as boas práticas de EaD possam ser visualizadas. Outro aspecto permitiu reflexão sobre como construir a equidade com os cursos presenciais e trabalhar com os alunos nas dimensões do ensino, da pesquisa e da extensão de forma indissociável.

\section{Referências bibliográficas}

Ciavatta, Maria \&Ramos, Marise. (2012). A "era das diretrizes": a disputa pelo projeto de educação dos mais pobres. Revista Brasileira de Educação v. 17 n. 49, 11-37 jan.-abr. Disponível em:http://www.scielo.br/pdf/rbedu/v17n49/a01v17n49.pdf. 
Creswell, John W. (2007). Projeto de Pesquisa - Métodos qualitativos, quantitativo e misto.Porto Alegre: Artmed.

Neves, et al. (2012). Educação a distância no CAED\UFMG: gestão e práticas integradoras. In: Fidalgo, et al. Educação a distância: Tão longe, tão perto. Belo Horizonte: CAED-UFMG.

Mill, D., \& Pimentel, N. (2010).Educação a distância: desafios contemporâneos. São Carlos: EdUFSCar.

Monteiro, Hugo. (2012). Diálogo, investigação e emancipação: percurso partilhado. In: MúRIAS, Claudia e KONING, Marijke. Lideranças partilhadas- Percurso de Literacia para a igualdade de gênero e qualidade de vida. Porto: Livpsic. 